not certain anymore, because trust in the validity of their assessments is challenged.

In recent years, an inflation of assessments occurred in academia: indicators, evaluations, reviews, rankings, ratings, and tests, etc. The credibility of these assessments is on the decline, because universities yield to pressures of bad evaluations rather than counteract collectively.

For example, irresponsible producers of rankings succeed by and large in dictating erratic criteria of world class universities. Moreover, they reinforce the view that the future of higher education and research depends on its elite, whereas mass higher education is residual.

Similarly, universities yield to the notion that academics should strive for visibility in peer-reviewed journals thus indicating their productivity. Again, they accept by and large that erratic lists of top journals are manipulated. Thereby, they reinforce the view that quality according to the internal views of academia is important and relevance can be ignored in the knowledge society.

There is an additional problem of a structural nature: can universities preserve trust as regards the key element of student assessment-i.e., the granting of degrees? Actually, the courses of study become more flexible. Some students acquire relevant competences prior to enrollment and get credits for prior learning. Moving from one university to another during the course of study, a highly appreciated tradition in Germany, gets more popular in various countries. Internships-i.e., periods of learning and experience outside higher education-often become mandatory. Opportunities increase to take individual courses at other universities-e.g., through Massive Open Online Courses (MOOCs). Study periods abroad gain popularity. In sum, the proportion of study time spent at the degree-granting institution declines. As a consequence, single universities might loose their credibility. Their capability might be questioned of assessing properly the competences acquired at different locations. Subsequently, a need might be felt for organizations in charge of consulting and assessing students, which are independent from universities.

Institutions of higher education face a decline of status on the way toward the knowledge society, not only as a consequence of their shrinking share in the overall knowledge production and dissemination, but also because trust declines that academics and higher educations institutions themselves assess the results of research, teaching, and learning properly. The multitude of evaluations, rankings, and indicators actually might be increasingly externally controlled, if the visible distortions cannot be counteracted by universities and academic profession. Moreover, the last resort of academic power — that of degree granting — might erode as well, if the changing context of teaching and learning does not lead to new ways of guidance and assessment

\section{Will the Ranking Game Continue After a Decade?}

\section{AkiYoshi Yonezawa}

Akiyoshi Yonezawa is associate professor, Graduate School of International Development, Nagoya University, Japan. E-mail: yonezawa@ gsid.nagoya-u.ac.jp.

Approximately I5 years ago, when international university rankings were still in their infancy, only a limited number of experts expected the wide and significant impact world university rankings would have on universities, governments, and the public. Currently, ranking status is considered mandatory information when seeking university partnerships and collaborations. Even if a country does not have universities with top rankings, governments frequently refer to ranking positions when they award national scholarships or recruit new staff members. Will the ranking game still continue after Io years? Yes, but probably in a very different form.

The ongoing phenomenon of universities and individuals seeking world-class environments for learning and researching will continue. Therefore, the number of universities striving to establish world-class status will increase further. For example, in 20I4, the Japanese government began a Io-year project to support "Top Global Universities," which aims to get Io universities ranked within the top Ioo in the world.

At the same time, the environments surrounding universities have changed dramatically since the introduction of the Internet. Almost all newly created knowledge now becomes immediately accessible from anywhere in the world. Language barriers still exist, but the automation of translation is nearly at the stage of practical use. Even analyses and writings, a core part of knowledge creation, are becoming automated. Audiovisual materials and cloud-based learning tools are already merging into daily teaching, learning, and researching. Detailed activities of researchers can be monitored with relation to what he or she publishes, what kind of literature is published, which citations are used, and the impact of specific work. This information is often reported to the authors and also to university managers.

The ranking methodologies have also changed frequently, which has occurred partly through the rapid increase in information concerning university activities and also through a significant increase in "rankers" with diversified backgrounds. The results of university rankings are also becoming diversified. For example, in 2014, only two Japanese universities were ranked in the top roo Times Higher Education World University Rankings and Best Global Universities from US News and World Report, while three 
ranked in the Academic Rankings of World Universities by Shanghai Jiao Tong University, and five ranked in the QS World-Class University Rankings. What do these rankings mean? The results of international university rankings vary according to selected indicators and weights. The U-Multirank does not provide comprehensive rankings, and some rankings now allow users to choose indicators and weights. It is becoming common for ranking providers to publish subject-based rankings and other rankings based on specific themes.

The golden age of university ranking providers has likely passed. Users, including universities and governments, now have more options for searching ranking results that fit their purposes. If it works for a better understanding of the rich context of universities, then it is good. However, further convergences or standardization of diversified university characteristics should be avoided through the efforts of various stakeholders.

\section{Revisiting the Academic Marketplace}

\section{Maria YudKeVICH}

Maria Yudkevich is vice rector at the National Research UniversityHigher School of Economics, Moscow, Russian Federation. E-mail: zүudkevich@gmail.com.

For many decades, our image of the university was associated with the metaphor of the ivory tower. While this metaphor is deeply embedded in our minds, we do not challenge it. However, it is neither ivory nor tower anymore. Indeed, university identity and borders become more and more unclear and illusory. There are several reasons for that.

First, new teaching and learning technologies challenge the university monopoly on both fundamental and applied knowledge. The number of students that follow courses on major online educational platforms grow exponentially, and faculty in many universities have to think about adjusting their courses in a way that they are still attractive to students. While advantages of a strong university in the provision of teaching services are evident, massive middle-tier institutions must identify how to compete for the attention of prospective students-not only with other universities but also with online providers. With lower transaction costs of combining curriculum from different providers in different universities, will the best and most demanding students still enroll in one university or will they combine experiences from different universities?
Second, traditionally junior faculty hired to tenure-track positions had a good chance of obtaining tenure. Today, chances are substantially lower. The share of permanent positions is getting significantly smaller in many countries and the age of obtaining a first stable position is increasing.

The monopoly of universities in producing basic research is also challenged by nonuniversity research organizations and corporations. These organizations compete for the best scholars and offer them competitive conditionsin some cases, including long-term employment-both in terms of salaries and opportunities for research.

Finally, there is an increasing pressure of productivity performance criteria and the need for constant search of external funding opportunities. This pressure may negatively affect academic norms of excellence, which assume the intrinsic motivation for the search of new knowledge and push universities toward considering faculty more as employees with clear performance indicators than as a community of scholars.

Massification of higher education leads to a substantial growth in a number of universities and also contributes to their diversity. Will universities from different parts of the quality continuum still recognize each other as species of one type in 20 years? Will there be much in common between top-tier research universities and those elsewhere in the academic hierarchy? Are we about to have traditional research universities becoming rare exceptions among numerous institutions of "used-to-be-university organizations"?

Since universities have been among the most stable organizations across the centuries, we might expect they will exist into the future. However, the questions are what will be their borders, how will their organizational identity be defined, and will the best and brightest minds be willing to come to work there.

\section{The Global Knowledge Soci- ety: Conflict Between Instru- mental and Principled Rea- son?}

\section{Pavel Zgaga}

Pavel Zgaga is professor at the Center for Educational Policy Studies at the University of Ljubljana and former minister of education, Slovenia. E-mail: pavel.zgaga@guest.arnes.si. 